\title{
Responses of a top and a meso predator and their prey to moon phases
}

\author{
Vincenzo Penteriani - Anna Kuparinen • Maria del Mar Delgado · Francisco Palomares • \\ José Vicente López-Bao · José María Fedriani · Javier Calzada · Sacramento Moreno • Rafael Villafuerte • \\ Letizia Campioni · Rui Lourenço
}

\begin{abstract}
We compared movement patterns and rhythms of activity of a top predator, the Iberian lynx Lynx pardinus, a mesopredator, the red fox Vulpes vulpes, and their shared principal prey, the rabbit Oryctolagus cuniculus, in relation to moon phases. Because the three species are mostly nocturnal and crepuscular, we hypothesized that the shared prey would reduce its activity at most risky moon phases (i.e. during the brightest nights), but that fox, an intraguild prey of lynx, would avoid lynx activity peaks at the same time. Rabbits generally moved further from their core areas on darkest nights (i.e. new moon), using direct movements which minimize predation risk. Though rabbits responded to the increased predation risk by reducing their activity during the full moon, this response may require several days, and the moon effect we observed on the
\end{abstract}

V. Penteriani (\&) · M. del Mar Delgado · F. Palomares ·

J. V. López-Bao · J. M. Fedriani · L. Campioni · R. Lourenço

Department of Conservation Biology, Estación Biológica de Doñ

ana (EBD-C.S.I.C.), c/Americo Vespucio s/n, 41092 Seville,

Spain

e-mail: penteriani@ebd.csic.es

V. Penteriani

Finnish Museum of Natural History, Zoological Museum,

University of Helsinki, FI-00014 Helsinki, Finland

A. Kuparinen

Department of Environmental Sciences, University of Helsinki, FI-00014 Helsinki, Finland

\author{
A. Kuparinen \\ Department of Biosciences, University of Helsinki, \\ FI-00014 Helsinki, Finland
}

M. del Mar Delgado

Department of Biosciences, Metapopulation Research Group,

University of Helsinki, FI-00014 Helsinki, Finland rabbits had, therefore, a temporal gap. Lynx activity patterns may be at least partially mirroring rabbit activity: around new moons, when rabbits moved furthest and were more active, lynxes reduced their travelling distances and their movements were concentrated in the core areas of their home ranges, which generally correspond to areas of high density of rabbits. Red foxes were more active during the darkest nights, when both the conditions for rabbit hunting were the best and lynxes moved less. On the one hand, foxes increased their activity when rabbits were further from their core areas and moved with more discrete displacements; on the other hand, fox activity in relation to the moon seemed to reduce dangerous encounters with its intraguild predator.

\section{J. V. López-Bao}

Grimsö Wildlife Research Station, Department of Ecology, Swedish University of Agricultural Sciences,

73091 Riddarhyttan, Sweden

\section{J. M. Fedriani}

Department of Ecological Modelling, Helmholtz Centre for Environmental Research GmbH-UFZ, Permoserstrasse 15, 04318 Leipzig, Germany

\section{J. Calzada}

Departamento de Biología Ambiental y Salud Pública, Universidad de Huelva, Avda. Fuerzas Armadas s/n, 21071 Huelva, Spain

\section{S. Moreno}

Department of Biodiversity Conservation and Applied Biology, Estación Biológica de Doñana, C.S.I.C, c/Americo Vespucio s/n, 41092 Seville, Spain 
Keywords Carnivore coexistence - Intraguild predation · Lunar cycle · Predator-prey interactions · Top/ mesopredators

\section{Introduction}

Predator-prey interactions are extremely complex because they are jointly determined by the effect of individual characteristics (e.g. behaviour, physiological condition, phenological traits, human activities), external factors (e.g. landscape, seasons, weather conditions), and certain properties of both the predator and prey populations, such as population demography or the spatial and temporal distribution of individuals (Abrams 2000; Caro 2005; Lima 2002). Predator-prey interactions play a crucial role in animal populations (e.g. Fretwell 1987; Sih et al. 1998), primarily because: (1) predation is one of the most common causes of mortality (and, for prey, there is strong selection pressure towards efficient antipredator defences); and (2) predators' fitness and survival depend strictly on their hunting efficiency. Moreover, predator-prey interactions have deeply influenced the evolution of life history traits and reproductive strategies of interacting species, since successful antipredator behaviours can produce selection for predator traits that can circumvent such prey defence mechanisms (Vermeij 1987).

For the abovementioned reasons, predator-prey interactions have been among the most frequently studied topics in animal ecology and behaviour (e.g. Sih et al. 1998; Lima 2009; Abrams 2000; Caro 2005), and represent fertile ground for theoretical explorations (e.g. Hugie and Dill 1994; van Baalen and Sabelis 1999; Bouskila 2001; Russell et al. 2009). Since the earliest explorations of predatorprey population dynamics by Lotka, Volterra and Gause (Taylor 1984), our know-how of such interactions has increased via the work on:

1. Predator-maintained cycles of prey abundance (e.g. Krebs et al. 1995).

2. The role of predation in regulating species diversity (e.g. Paine 1966).

3. Whether, and, if so, how prey defence strategies change over ontogeny (e.g. Pettersson et al. 2000; Relyea 2003a).

\footnotetext{
$\overline{\text { R. Villafuerte }}$

Instituto de Investigación en Recursos Cinegéticos, IREC (CSIC-UCLM-JCCM), Ronda de Toledo s/n, 13005 Ciudad Real, Spain

R. Lourenço

Instituto de Ciências Agrárias e Ambientais Mediterrânicas (ICAAM), Laboratório de Ornitologia (LabOr), Universidade de Évora, Núcleo da Mitra, Ap. 94, 7002-554 Évora, Portugal
}

4. Prey responses to multiple predators (e.g. Sih et al. 1998; Turner et al. 1999; Relyea 2001, 2003b).

5. Anthropogenic or natural changes in the landscape that can influence predator hunting success and access to forage resources for prey species (e.g. Pedersen et al. 2010; Smee 2012).

6. Predatory interactions among top predators (i.e. intraguld predation; Polis et al. 1989) that can play a crucial role in structuring vertebrate communities through the suppression or release of either the mesopredator or the prey (Palomares et al. 1995; Crooks and Soulé 1999; Fedriani et al. 2000; Sergio et al. 2003).

7. Non-lethal effects determined by the mere presence of predators in ecological systems (e.g. Lima 1998; Peacor and Werner 2004; Pangle et al. 2007; Peckarsky et al. 2008), which may alter prey behaviours (e.g. Crowl and Covich 1994; Doncaster 1994; Sergio et al. 2007; Morosinotto et al. 2010), reduce feeding activity (e.g. Kohler and McPeek 1989), and induce physiological stress responses of prey under a stressful situation (e.g. Skelly and Werner 1990; Monclús et al. 2009).

However, despite the many advances in this field and the several hundred papers on predator-prey interactions published in the past 30 years, at the beginning of the current century we have still to consider our understanding of predator-prey interactions to be limited, mainly because these interactions have been less frequently analysed from a predator perspective (Lima 2002).

This constraint is reinforced by the lack of comparative studies addressing the behaviours of predators and their chief prey (but see Berger-Tal et al. 2010; Kotler et al. 2010), as well as the extent to which behaviours are adaptative to different scenarios and the external constraints under which predator-prey interactions may occur. Among the factors playing a role in shaping the activity of mostly nocturnal predators and prey, moon cycles have recently been shown to affect both predator and prey strategies and behavioural choices (e.g. Brown and Kotler 2004; Kotler et al. 2010; Penteriani et al. 2011 and reference therein). In fact, the changes in illumination conditions determined by the varying brightness of the moon during the lunar cycle generally force prey to be less active and more vigilant and to feed in safer habitats near the time of the full moon (e.g. Vasquez 1994; Brown and Kotler 2004; Griffin et al. 2005). Indeed, on bright moonlit nights: (1) prey shift to more apprehensive foraging strategies (Kotler et al. 2010), and/or (2) are less active (Clarke 1983; Sábato et al. 2006; Berger-Tal et al. 2010). Consequently, selection pressures likely exist on predators to be more active (but see Sábato et al. 2006), as they should search more intensively for prey (although this activity increase depends on the way predators search for their prey, and is 
more likely for active than ambush foragers). However, the predators certainly benefit at the same time from high light levels when hunting (Clarke 1983; Kotler et al. 1988). Actually, predators are most lethal during the brightest hours of the night (Kotler et al. 2002). Despite the longterm interest in the influence of lunar phases on prey behaviour and antipredator strategies (reviewed in Penteriani et al. 2011), less information is available on the response of predators to moonlight (but see Grassman et al. 2005; Di Bitetti et al. 2006; Sábato et al. 2006; Mukherjee et al. 2009). In addition, the interest in the response of predators to moon phases is increased by the evidence that predators at the same trophic level can prey upon each other (with or without consumption; Polis and Holt 1992), a phenomenon that has paramount consequences (e.g. Schmitz et al. 1997). Yet, no study to date has assessed the joint responses of top predators, mesopredators and their shared prey to lunar phases (but see Mukherjee et al. 2009).

By taking advantage of long-term monitoring data of a top predator species, the Iberian lynx (Lynx pardinus), a mesopredator, the red fox (Vulpes vulpes), and their shared prey, the European rabbit (Oryctolagus cuniculus), in the same area (Doñana National Park), we analysed and compared whether the responses of these predators and prey to moon phases are adaptative. Locally, these two sympatric predators (e.g. Fedriani et al. 1999) feed largely upon rabbits (Delibes 1980; Rau et al. 1985; Fedriani et al. 1999) and, therefore, their activity should be synchronised with rabbit activity. However, some differences in the life history of these species may also influence their behaviours. For example, rabbit density determines lynx but not red fox reproductive success (Palomares et al. 2001) and population density (Rodríguez and Delibes 2002). Thus, lynxes should be under stronger selection pressure than foxes to maximize rabbit hunting success by, for instance, following prey responses to lunar phases. Moreover, lynxes in Doñana are mainly crepuscular (Beltran and Delibes 1994; López-Bao et al. 2011) and habitat specialists (Palomares et al. 2000), while red foxes are mainly nocturnal (but they also have crepuscular activity), and habitat generalist (Ginsberg and Macdonald 1991; Fedriani et al. 1999). Finally, since rabbits are also crepuscular (Lombardi et al. 2003), selection for antipredator behaviour is likely to occur in our study system.

For the purposes of this study, we were interested in detecting and comparing general species-specific patterns of behaviours under the effect of moonlight rather than patterns at the level of populations or individuals. By focusing primarily on movement patterns and rhythms of activity, we made a general prediction. Predators and their prey should show opposite activity peaks during moon cycles because of the changing night brightness. We would therefore expect an increase in the activity of predators near the time of the full moon as a response to the reduced level of rabbit activity (Kolb 1992; Twigg et al. 1998). The same pattern could be predicted during the new moon, because dark nights hamper prey location and capture (Clarke 1983; Kotler et al. 1988, 1991). However, since mesopredators are also potential prey (red foxes may be killed by lynx; Palomares and Caro 1999), they also need to trade-off between food and safety: the same behavioural choices and strategies that make an animal an efficient predator may increase its risk of becoming a prey (Lima 1998). Thus, natural selection should produce adaptive flexible behaviours in mesopredators, allowing them to act according to the trade-off between the benefits of energy intake and the cost of a premature death (Sih 1987; Lima and Dill 1990). Under this perspective, we expected that red fox patterns of activity would be sensitive to the new moon, i.e. that red foxes should be more active on the darkest nights. In particular, we expect that:

1. During the brightest nights, rabbits will reduce their movement rate, increasing activity around new moons because of the safer conditions offered by darkness.

2. Lynx will show a pattern of activity opposite to that of rabbits, e.g. increase their displacements when rabbits are less mobile.

3. Red foxes will show a trade-off in their activities due to the need to increase encounters with rabbits and decrease the risk of being killed by a lynx.

In addition to the main hypothesis and expectations, we suppose that individual activity should also vary due to some other aspects acting on the individuals, like several internal (e.g. age, sex, the need for foraging efficiency during reproduction), as well as external factors (e.g. landscape structure and composition).

\section{Materials and methods}

\section{Study area}

Radio-tracking of all three species was carried out in the Doñana National Park (south-western Spain). Two main environments characterize the Doñana area: scrubland and marshland. The scrubland area, on sandy soils, is made up of patchy, heterogeneous landscapes with a great variety of different habitats. The marshland remains flooded for a portion of the year and it is not relevant for this study. 
Collection of data from radio-tagged individuals: predators

\section{Lynxes}

We radio-tagged 32 lynxes (15 males and 17 females) from a population that has been intensively studied during the past 25 years (e.g. Ferreras et al. 1997, 2004; Palomares et al. 2001; López-Bao et al. 2010). Between 1993 and 2007, lynx were captured with box traps (509509200 cm) baited with live domestic rabbits subjected to sanitary control. Trapped lynxes were checked for any damage associated with the capture (no damage was found) and were fitted with collars, keeping the compromise of a weight $(200 \mathrm{~g})$ less than $5 \%$ of the absolute weight of the smallest lynx captured (Kenward 2001). Radio-tracking procedures were the same for all individuals. Lynxes were located according to two schedules: (a) between two and four times per week; and (b) during weekly intensive 24-h radio-tracking sessions, where we recorded their position and activity on an hourly basis (Ferreras et al. 1997; Palomares et al. 2001; López-Bao et al. 2010). Lynx activity was determined by means of activity sensors incorporated into the collars. Overall, lynx were tracked during a total of 246 nights, and a total number of 2,082 nocturnal locations were collected.

\section{Foxes}

We radio-tagged 33 red foxes (18 males and 15 females), which were followed during 5 years (1993-1997). Red foxes were captured using coil-spring traps (Victor no. 2; Woodstream, PA) and box traps baited with pieces of chicken. Once captured, the animals were fitted with radiocollars (150 g) equipped with an activity sensor; the tracking system and procedures for red foxes were similar to those described for lynx (see also Ferreras et al. 1997). Intensive radio-tracking periods were conducted during 86 nights (for 902 locations), during which red fox locations were determined at 1 -h intervals.

\section{Collection of data from radio-tagged individuals: prey}

\section{Rabbits}

A total of 55 individuals (32 males and 23 females) were trapped and radio-tagged during 2 years (1993-1994). Rabbits were trapped and managed following the methods described in Lombardi et al. (2003, 2007). During trapping sessions, rabbits were flushed out of their warrens by muzzled ferrets (Mustela furo) and then captured in nets. Each rabbit was equipped with a 20-g radio-collar with activity sensors (Biotrack) and the weight of the transmitters were less than $3 \%$ of the weight of the smallest adult male (750 g; mean $\pm \mathrm{SD}=$ $990 \pm 37.4 \mathrm{~g}$ ). We obtained three radio locations per week from each rabbit during regular monitoring periods and from seven to 14 locations per week during intensive monitoring periods (30 days every 3 months; Lombardi et al. 2003, 2007). The tagged individuals were tracked during 120 nights, for a total of 414 nocturnal locations.

\section{Moon phases}

The different phases of the lunar cycle were calculated as in Penteriani et al. (2011). In particular: (1) the daily moon phase at the geographic location of the study area was obtained from the Naval Oceanography Portal (http://aa.usno.navy.mil/data/docs/RS_OneDay.php) and expressed in terms of the fraction of the moon disk illuminated and whether the moon was waxing or waning; (2) the fraction of the moon disk illuminated was converted into radians (h), with one lunar cycle corresponding to a gradual change from 0 to $2 p$ radians $(0$ and $2 p$ radians correspond to the full moon, and $\mathrm{p}$ radians corresponds to the new moon). $\operatorname{Cos}(\mathrm{h}), \sin (\mathrm{h}), \cos (2 \mathrm{~h})$ and $\sin (2 \mathrm{~h})$ transformations were included in the statistical model as explanatory variables to investigate the possible lunar effects on individual activity throughout the lunar cycle (deBruyn and Meeuwig 2001; Kuparinen et al. 2010).

\section{General movement patterns and rhythms of activity}

Nocturnal movement patterns and the rhythms of activity of the three target mammals were calculated separately and at two different spatial scales, the home range and the core area(s). For each night of radio tracking, we first estimated the home range size using fixed-kernel methods (Worton 1989) with a least squares cross-validation process to determine the optimal value of the smoothing parameter for a given kernel and sample size. To establish the home range boundaries, we used density isopleth values of $90 \%$ (Seaman and Powell 1996). We characterised the internal structure of the home ranges by estimating the core area(s) of each home range, defined by the $50 \%$ density isopleths. Movements at the home range spatial scale were described by two variables (Delgado et al. 2010a, b; Penteriani et al. 2011): (a) total distance, the sum of the distance between successive steps on the same nightly path; and (b) speed, the value obtained by dividing the step distance by the time interval between successive locations. To determine the rhythms of activity, we used: (1) core area activity, the time an individual spent in the core area(s); (2) the number of movements within the core area(s); and (3) percentage of locations of active individuals, which was determined by means of activity sensors incorporated into the collars. 
Status and internal state of individuals

Lynxes

We considered four explanatory variables representing additional potential sources of variation in individual activity:

(a) The different phases of the biological cycle. We defined three seasons according to lynx behaviour and rabbit abundance (López-Bao et al. 2008)—mating season and medium rabbit abundance (DecemberMarch; 1); cub-rearing and high rabbit abundance (April-July; 2); females accompanied by juveniles, pre-dispersal phase and low rabbit abundance (August-November; 3).

(b) Lynx age. Since age was known for all individuals (Ferreras et al. 2004; Palomares et al. 1996; LópezBao et al. 2009), lynx were categorized as young ( 2 years, all individuals in the predispersal phase; Ferreras et al. 2004), or adults (C2 years).

(c) Sex of lynx.

(d) Status of lynx, i.e. resident or dispersing individual. We considered all adult lynx maintaining site fidelity for at least 10 months as resident individuals (Palomares et al. 2000).

Because of the increasing experience of juvenile individuals (López-Bao 2010), both age and status can potentially affect individual behaviour.

Foxes

Following Fedriani et al. (1999) we included the following five additional variables:

(a) Three different seasonal periods influencing red fox behaviour-mating season (November-February; 1), cub rearing (March-June; 2), and dispersal (JulyOctober; 3).

(b) Two different periods corresponding to high (1) and low (2) rabbit abundance.

Additionally, we also included:

(c) Sex of foxes.

(d) Age of foxes-juvenile ( 1 year), subadult (1-2 years), adult (C2 years)—which was based on tooth wear.

(e) The activity status of the fox (active or inactive), which was based on the collar-sensor signal.

Rabbits

Five additional explanatory variables were also included: (a) The different phases of the biological cycle for rabbits-pre-breeding (when the number of reproducing females is relatively low; November-January; 1); breeding (February-May; 2); post-breeding (JuneJuly; 3); non-breeding (when the number of reproducing females is close to zero; August-October; 4).

(b) Sex of rabbits (all animals were sexed based on their external genitalia).

(c) Age of rabbits (determined by individual weight) (Soriguer 1981; Villafuerte 1994).

In addition, two specific variables for the rabbit were considered, which might also affect individual behaviours:

(d) Status of rabbits [representing a native (1) or a reintroduced individual (2)].

(e) A rabbit's location [inside (1) or outside (2) a fenced area; the fence never restricted the access of lynxes or foxes to the area inhabited by rabbits].

External cues influencing individual activity

For the two predators and the prey, we tested the possible effect of habitat heterogeneity and composition on individual behaviour. We used edge density (i.e. the total length of the patch edge per unit area within each landscape) and Shannon's diversity index as proxies for the effect of habitat heterogeneity (Donovan et al. 1995; Elkie et al. 1999; Kie et al. 2002; Anderson et al. 2005). To evaluate habitat composition, we first reclassified the map into ten main land cover elements: crop areas, water bodies, eucalyptus forest, dense scrubland, open scrubland with scattered trees, pasture, open scrubland with pasture, sand dunes, woody crops and herbaceous crops. Then we calculated the proportion of each habitat type within the area traversed by individuals on each radio-tracking session. The calculated home range areas (in raster format; cell size: $0.590 .5 \mathrm{~km}$ ) were used as a basic input data layer for measuring all landscape metrics. Both landscape structure and composition were estimated using ArcMap in ARCGIS version 9.0. Because habitat changes over the study years were minimal in Doñana, we did not use yearspecific habitat cover.

\section{Statistical analyses}

To analyse how the lunar cycle may affect individual behaviour, we built general linear mixed models with movement parameters and rhythms of activity as the dependent variables and (1) moon phase, (2) individual status/internal state, and (3) external cues as the explanatory variables. Given that the probability to have a cloudy night is equally distributed over the study period and, consequently, among all moon phases, we considered such 
Table 1 Model outputs of the tested variable for rabbits, lynxes and red foxes

\begin{tabular}{|c|c|c|c|c|c|c|c|c|c|c|c|c|c|c|c|}
\hline & \multicolumn{5}{|c|}{ Moon phase } & \multicolumn{5}{|l|}{ Status/internal } & \multicolumn{5}{|l|}{ External cues } \\
\hline & & b & SE & $\mathrm{t}$-value & CIs & & b & SE & t-value & CIs & & b & SE & $\mathrm{t}$-value & CIs \\
\hline \multicolumn{16}{|l|}{ Rabbits } \\
\hline \multirow[t]{3}{*}{ Total distance } & $\operatorname{Cos}(\mathrm{h})$ & 44.81 & 16.17 & 2.77 & 13.11, 76.50 & Period $2^{\mathrm{b}}$ & -107.57 & 39.44 & -2.73 & $\begin{array}{c}-184.87,- \\
30.28\end{array}$ & ED & $-2,289.52$ & 372.58 & -6.15 & $\begin{array}{c}-3,019.76,- \\
1,559.28\end{array}$ \\
\hline & $\operatorname{Sin}(\mathrm{h})$ & -369.17 & 46.57 & -7.92 & $\begin{array}{c}-460.45,- \\
277.89\end{array}$ & Period $4^{b}$ & 292.84 & 40.16 & 7.29 & 214.12, 371.55 & & & & & \\
\hline & & & & & & Status $^{c}$ & 64.22 & 23.03 & 2.79 & $19.07,109.37$ & & & & & \\
\hline Speed & $\operatorname{Sin}(2 \mathrm{~h})$ & -0.68 & 0.16 & -4.32 & ** & Period $4^{\mathrm{b}}$ & 0.89 & 0.14 & 6.59 & $* *$ & ED & -8.51 & 1.32 & -643 & ** \\
\hline \multirow[t]{2}{*}{$\mathrm{T}_{\text {core area }}$} & $\operatorname{Cos}(\mathrm{h})$ & 69.30 & 25.36 & 2.73 & $19.60,119.00$ & Period 2, $1 \& 3^{b}$ & -129.81 & 53.86 & 16.53 & $\begin{array}{c}-235.38,- \\
24.25\end{array}$ & No effect & & & & \\
\hline & $\operatorname{Sin}(\mathrm{h})$ & 87.12 & 37.74 & 2.31 & 13.16, 161.08 & & & & & & & & & & \\
\hline $\begin{array}{l}\mathrm{N}_{\text {core area }} \\
\text { Lynxes }\end{array}$ & \multicolumn{14}{|c|}{ Lynxes } & \\
\hline \multirow[t]{3}{*}{ Total distance } & No effect & & & & & No effect & & & & & ED & -6.91 & 1.55 & -4.46 & $-9.95,-3.87$ \\
\hline & & & & & & & & & & & SDI & 858.35 & 195.09 & 4.40 & $475.97,1,240.72$ \\
\hline & & & & & & & & & & & $\begin{array}{l}\text { Habitat } \\
\text { type }^{\mathrm{d}}\end{array}$ & -36.39 & 17.82 & -2.04 & $-71.32,-1.46$ \\
\hline \multirow[t]{2}{*}{ Speed } & No effect & & & & & $\operatorname{Age}^{f}$ & 0.45 & 0.12 & 3.67 & $* *$ & $\mathrm{ED}$ & -0.002 & 0.0004 & -4.69 & $* *$ \\
\hline & & & & & & & & & & & SDI & 0.34 & 0.05 & 6.93 & $* *$ \\
\hline \multirow[t]{2}{*}{$\mathrm{T}_{\text {core area }}$} & No effect & & & & & Period $2 \& 3^{b}$ & 65.83 & 25.19 & 2.61 & $16.46,115.19$ & No effect & & & & \\
\hline & & & & & & Age $^{f}$ & -115.78 & 41.33 & -2.80 & $\begin{array}{l}-196.79,- \\
34.76\end{array}$ & & & & & \\
\hline \multirow[t]{2}{*}{$\mathrm{N}_{\text {core area }}$} & $\operatorname{Sin}(2 \mathrm{~h})$ & 0.16 & 0.06 & $2.92^{\mathrm{a}}$ & * & Period $2 \& 3^{b}$ & -0.28 & 0.07 & $-3.69^{\mathrm{a}}$ & $* *$ & No effect & & & & \\
\hline & $\operatorname{Cos}(\mathrm{h})$ & -0.14 & 0.05 & $-2.91^{\mathrm{a}}$ & $* *$ & & & & & & & & & & \\
\hline \multicolumn{16}{|l|}{ Foxes } \\
\hline \multirow{2}{*}{ Total distance } & No effect & & & & & Sex (female) & 560.92 & 243.33 & 2.30 & $83.99,1,037.85$ & ED & -28.69 & 2.92 & -9.82 & $-34.42,-22.97$ \\
\hline & & & & & & Period $^{\mathrm{g}}$ & 658.34 & 232.04 & 2.84 & $203.54,1,113.14$ & SDI & $2,099.23$ & 296.32 & 7.08 & $1,518.45,2,680.01$ \\
\hline \multirow[t]{2}{*}{ Speed } & No effect & & & & & No effect & & & & & ED & -0.013 & 0.001 & -10.05 & $-0.02,3.21$ \\
\hline & & & & & & & & & & & SDI & 0.87 & 0.13 & 6.64 & $0.57,10.9$ \\
\hline $\mathrm{T}_{\text {core area }}$ & No effect & & & & & No effect & & & & & ED & -0.46 & 0.21 & -2.15 & $-0.89,-0.04$ \\
\hline $\mathrm{N}_{\text {core area }}$ & No effect & & & & & No effect & & & & & ED & -0.004 & 0.0009 & -4.16 & $* *$ \\
\hline $\begin{array}{l}\text { Activity } \\
\text { status }\end{array}$ & $\operatorname{Cos}(\mathrm{h})$ & -0.24 & 0.11 & -2.08 & * & Period $^{\mathrm{g}}$ & 0.76 & 0.22 & 3.37 & $* *$ & Habitat type $^{e}$ & -0.014 & 0.004 & 3.77 & $* *$ \\
\hline \multicolumn{16}{|c|}{ CI Confidence interval, ED edge density, SDI Shannon's diversity index } \\
\hline \multicolumn{16}{|c|}{$* \mathrm{P} \backslash 0.01, * * \mathrm{P} \backslash 0.001$} \\
\hline \multicolumn{16}{|c|}{ a-value } \\
\hline \multicolumn{16}{|c|}{${ }^{\mathrm{b}}$ Factor levels were joined in the model simplification process } \\
\hline \multicolumn{16}{|c|}{${ }^{\mathrm{c}}$ Reintroduced rabbits } \\
\hline \multicolumn{16}{|c|}{${ }^{\mathrm{d}}$ Cultivated habitat } \\
\hline \multicolumn{16}{|c|}{ e Dense habitat } \\
\hline \multicolumn{16}{|c|}{ Adult individuals } \\
\hline${ }^{\mathrm{g}}$ Spring and sun & & & & & & & & & & & & & & & \\
\hline
\end{tabular}


variation to lead to additional noise, which is likely to weaken the signal strength in our results rather than to create systematic biases. The total distance and time spent in the core area were modelled using linear mixed models with follow-up time (tsessions) included as an offset. This is because total distance and time spent in the core area depend on the duration of the radio-tracking session and, then, these variables need to be standardized by tsessions. Hence, the variation arising from different lengths of the follow-up session was accounted for by considering the length of the period as an offset variable. To include the offset function, the linear mixed models were built using the lmer function, and therefore, confidence intervals (25\% CI and $95 \% \mathrm{CI}$ ), not P-values, are reported for these models. To ensure normality, both total distance and speed were log-transformed. We used generalised linear mixed model to analyse the number of movements in the core area(s), assuming quasi Poisson distributed data (to control for the overdispersion), with the logarithm of the follow-up time (tsessions) included as an offset (normal choice in Poisson models). Because we had repeated measures of the same individual within and between years, we considered the individual and year as random effects. Because only a few individuals occupied territories that partially overlapped, we could not consider the territory as a random factor (i.e. the number of levels of this factor was not enough to get an accurate characterization of the mean and variance; Zuur et al. 2009). Following Pinheiro and Bates (2004), the significance values of random effects were estimated using the Akaike information criterion. As

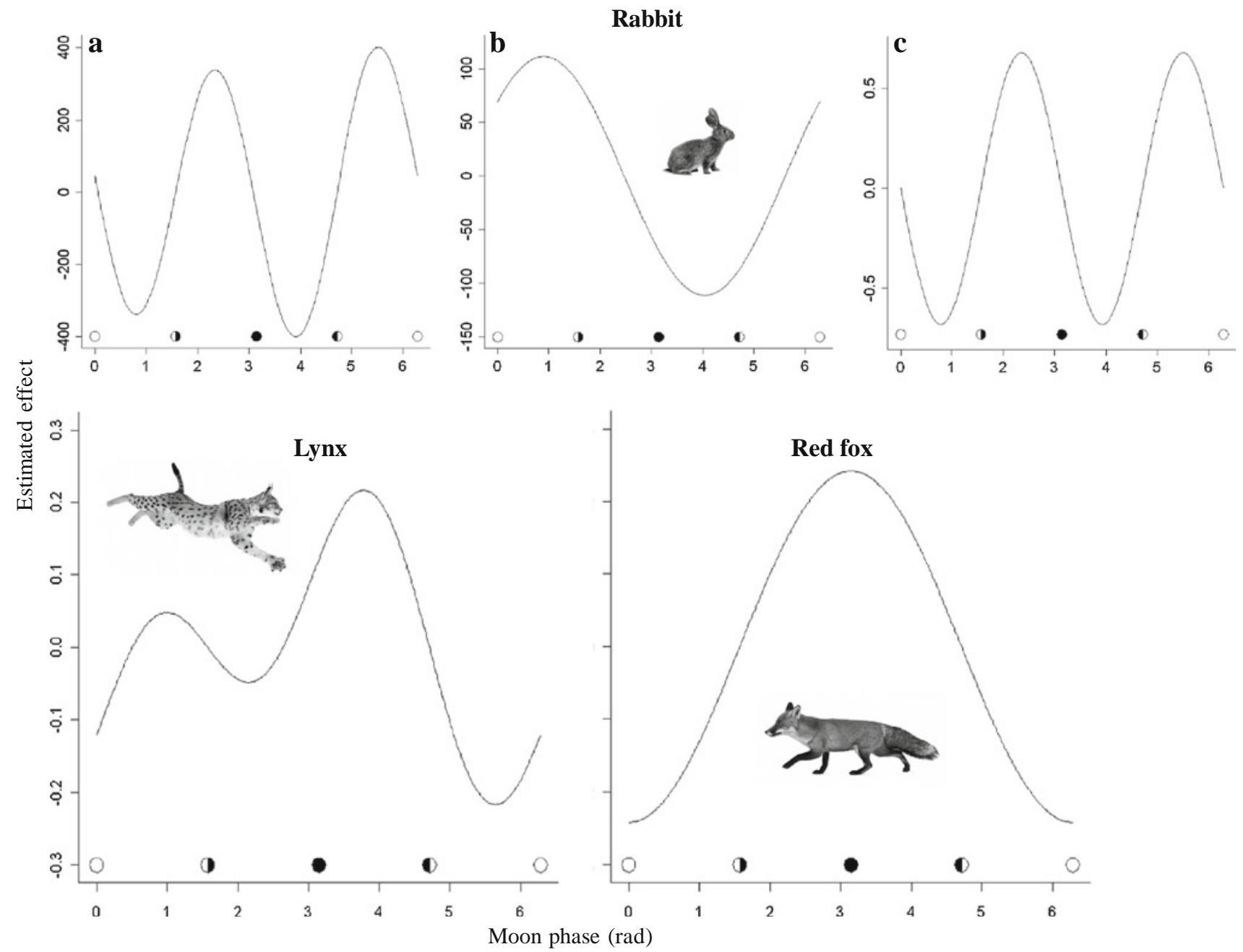

Fig. 1 Moon-phase effect on rabbits: a the total distance moved during the night shows two peaks within a lunar cycle, with the higher peak during the darker period, whereas b the time spent in the core area at night increases with the intensification of nocturnal brightness; log-transformed speed at night (c, solid line) shows a pattern similar to that of the total distance. The pattern is slightly shifted to the right

of the full (white circle)/new moon (black circle), i.e. there might be a delayed response to the full/new moon. The number of lynx nightly locations in the core area peaks near the time of the new moon, which is the darkest period, and is always lower near the brightest nights. The probability of finding an active red fox increases at new moon 
the random factor year did not improve the model's likelihood value, we built a less complex model class. As suggested by Crawley (2007): (1) model simplification was performed by backwards selection of variables from the full model, and (2) models were compared using likelihood ratio tests until a minimal adequate model was obtained. In the case of the different phases of the biological cycle factor, model reduction was performed by joining the factor levels closest to each other, after which nested models were compared using likelihood ratio tests until the minimal adequate model was found. For each analysis, we used slightly different sub-samples of the data. These subsamples represented those individuals for which it was possible to collect the specific information sought. The residuals of the final models were explored to verify the normality, homogeneity (except in the case of the generalised linear model), and independence assumptions. All statistical analyses were performed in R 2.10.1 statistical software (R Development Core Team 2009) with the nlme (Pinheiro et al. 2009), lme4 (Bates and Sarkar 2007) and MASS (Venables and Ripley 2002) packages. Statistical significance was set at a $\backslash 0.05$.

\section{Results}

\section{Moon phase effects}

Our analyses of rabbit radio-tracking data revealed that lunar cycle had a significant effect on the following response variables (Table 1): (1) the total distance moved during the night (intercept: $\mathrm{b} \pm \mathrm{SE}=-372.65 \pm 41.30$, tvalue $=-9.02$; CIs $-453.60,-291.71$; Fig. 1a); (2) the time spent at night in the $50 \%$ core area (intercept: $\mathrm{b} \pm \mathrm{SE}=-176.01 \pm 44.34$, $\mathrm{t}$-value $=-3.97$; CIs -262.91, -89.10; Fig. 1b); and (3) the movement speed (intercept: $\mathrm{b} \pm \mathrm{SE}=-1.11 \pm 0.13$, t-value $=-8.31$, $\mathrm{P} \backslash 0.0001$; Fig. 1c). Together, the effect of moon cycle on rabbit movement and rhythms of activity parameters seemed to determine three different behavioural strategies. First, at the time of the full moon, rabbit movement rate was low (i.e. short total distances and low speed; Fig. 1a, c, respectively) within their core area (Fig. 1b). Second, rabbits increase their movement activity (i.e. long total distances and high speed; Fig. 1a, c, respectively) both within and outside their core area (Fig. 1b) around new moon, when darkness potentially offers the safest opportunities for movement. Thirdly, on the darkest nights, rabbits moved far from their core area (Fig. 1b) and seemed to optimise this strategy by using oriented movement patterns, i.e. covering long distances away from their core area(s) by using few number of steps and, therefore, reducing the total distances moved (Fig. 1a). The rabbit pattern is slightly shifted to the right from the full/new moon, i.e. there might be a delayed response to the full/new moon and/or to predator activity peaks that correspond to the full/new moon (see below).

A significant moon effect was also found in the number of nightly locations in the core areas for lynxes (intercept: $\mathrm{b} \pm \mathrm{SE}=-4.84 \pm 0.08, \mathrm{z}$-value $=-58.68, \mathrm{P} \backslash 0.0001$; Fig. 1b; Table 1), which peaked near the time of the new moon (i.e. during the darkest period), clearly contrasting with the rabbit activity pattern. That is, lynxes moved further from core areas when rabbits were mostly active within their core areas. However, when rabbits moved away from the core areas, lynxes tended to move less by spending more time within their core area(s).

The effect of the moon cycle on red fox behaviour was weaker than for rabbit and lynxes, only indicating a slight increase of the probability of being active around new moon, i.e. when nights are darker (intercept: $\mathrm{b} \pm \mathrm{SE}=$ $-0.85 \pm 0.25, \quad$ z-value $=-3.36, \quad P \backslash 0.0001 ; \quad$ Fig. $1 \mathrm{c}$; Table 1). That is, red foxes showed the highest activity: (1) when rabbits mostly moved away from their core area(s); but (2) lynxes were moving less, due to longer settlement within the core area(s), which could have maximised and minimized encounters with fox prey (rabbit) and intraguild predator (lynx), respectively.

\section{Additional effects}

The moon's effect on the rabbits' nocturnal behaviour was also associated with different phases of the biological cycle (Table 1): the total distance moved during the night, time spent in the core areas and speed all increased during the non-breeding period. In addition, reintroduced rabbits tended to move longer distances than native individuals. Furthermore, the structure of the habitat, in particular edge density, also affected total distance and movement speed: rabbits moved short distances and at slow speed when crossing fragmented habitats.

Total distance moved by lynxes (intercept: $\mathrm{b} \pm \mathrm{SE}$ $=5,403.50 \pm 1,868.07$, $\mathrm{t}$-value $=-2.89$; CIs 1,742.15, 9,064.86; Table 1) and their movement speed (intercept: $\mathrm{b} \pm \mathrm{SE}=0.69 \pm 0.19, \quad \mathrm{t}$-value $=3.54, \quad \mathrm{P}=0.0004$; Table 1) were affected by habitat structure and composition. Lynxes moved short total distances and at slow speed when moving in fragmented but less diverse habitats, especially when crossing areas of cultivated crops. Additionally, movement speed was influenced by individual age, with adults generally moving faster than juveniles. The number of lynx nocturnal movements (intercept: $\mathrm{b} \pm \mathrm{SE}=-4.84 \pm 0.08, \mathrm{z}$-value $=-58.68, \mathrm{P} \backslash 0.0001$; Fig. 1b; Table 1) and the time spent (intercept: $\mathrm{b} \pm \mathrm{SE}=-315.30 \pm 37.84, \quad \mathrm{t}$-value $=-8.33 ; \quad$ CIs $-389.47,-241.14$; Table 1) within the core area were 
related to their biological cycle: individuals moved close to their core areas during the central phases of lynx reproduction (from kitten rearing to the pre-dispersal phase of juveniles).

Finally, fox movement behaviour was affected by several internal and external factors. Like rabbits and lynxes, foxes moved a short total distance (intercept: $\mathrm{b} \pm \mathrm{SE}=$ 2,369.87 \pm 292.18 , t-value $=8.11$; CIs 1,797.21, 2,942.53; Table 1) and at slow speed (intercept: $\mathrm{b} \pm \mathrm{SE}=$ $2.98 \pm 0.09$, t-value $=31.79$; CIs 2.80, 3.16; Table 1 ) in fragmented habitats. Individuals moved longer total distances in spring and summer, especially females (Table 1). The number of fox nocturnal movements (intercept: $\mathrm{b} \pm \mathrm{SE}=-0.0048 \pm 0.0009, \mathrm{z}$-value $=-4.16$; Table 1 ) and the time spent (intercept: $\mathrm{b} \pm \mathrm{SE}=-98.12 \pm 15.99$, $\mathrm{t}$-value $=-6.13$; CIs $-129.47,-66.77$; Table 1 ) within the core area were also related to the structure of the habitat: individuals spent less time within their core area when inhabiting fragmented habitats than when in continuous landscapes. Finally, the probability of being active was higher in spring and summer, especially when individuals were crossing dense habitats (Table 1).

\section{Discussion}

As expected, moon phases played a role in both predator and prey activity, potentially affecting predator-prey interactions. Three main points emerged from our analyses. Firstly, the moon has a stronger effect on the behaviour of the prey than on the behaviour of both species of predator. Because prey foraging and, more generally, prey displacements are undoubtedly riskier than predator movements, rabbit is the most constrained species during bright nights. We observed that the alternation of extremely different types of moonlight led to a complex anti-predatory rabbit strategy. On the darkest nights, rabbits took the risk to move further from their burrows (located in their core areas); however, they seemed to reduce the risk to be far from cover by moving with direct movements (i.e. they reduced the total distance they moved by decreasing the number of movement steps). That is, when the costs of movements were high, a safe movement strategy evolved to decrease the time spent in an inhospitable environment (Delgado et al. 2010a, b). Other studies have found that rabbit movements and activity are affected by predation risk (Kolb 1992; Twigg et al. 1998), which is one of the crucial, extrinsic factors influencing the behaviour of individuals and their habitat selection (Bos and Carthew 2003; Kotler 1997; Lima and Dill 1990).

Secondly, and due to the dependence of lynx on rabbits (Fedriani et al. 1999; López-Bao et al. 2008), the activity of lynxes and rabbits may be connected during the different moon phases. This pattern may be at least partially the result of the level of rabbit activity, which is higher during the darkest nights (Kolb 1992; Twigg et al. 1998). Consequently, the lynxes are not forced to move throughout their whole home range to find a prey, and their movements are thus mainly performed in the close surroundings of their core areas, which generally correspond to areas of high density of rabbits (Palomares et al. 2001).

Thirdly, the rather weak link between moon phases and red fox activity seems to indicate that fox patterns of activity are: (1) relatively more independent of those of rabbit, although foxes are more active when the conditions for rabbit hunting are the best; but (2) are inverse to the activity patterns of lynxes. There might be at least two not mutually exclusive explanations for these patterns. The first may be found in the characteristics of the diet and hunting behaviour of foxes. Because foxes are trophic generalists (Fedriani et al. 1999), their activity patterns are likely influenced by prey species other than rabbit (rodents, insects, etc.). In addition, red foxes, chase their mobile prey (Kleiman and Eisenberg 1973; Murray et al. 1995), which is typical of canids, and do not sit and wait like lynxes (Delibes 1980). Thus, red foxes would need to increase their activity during the darkest nights to elevate the probability of encountering rabbits, which would be further from their core areas and moving with more discrete displacements. Moreover, rabbit hunting may be less effective during bright nights, fox predation on rabbit being generally lower on full moon nights than during other moon phases (Molsher et al. 2000). Lastly, the opposite patterns of activity we recorded between the top and the mesopredator could represent a fox-avoidance strategy attained by temporal segregation: the mesopredator alters its activity times to avoid encounters with the top predator. In many systems, smaller predators forage at risk from top predators, which do not only kill or injure but may also induce fear, and this influence the behaviour and the ecology of mesopredators (Mukherjee et al. 2009). Actually, foxes perceive moonless nights to be safer and, when coexisting with top predators, tend to increase their activity on darker nights when top predators are less active (Mukherjee et al. 2009).

We consider it important to highlight that the lack of temporal overlap of our data does not affect our inferences and conclusions. This is because, for the purposes of this study, we were interested in detecting and comparing general species-specific patterns of activity under the effect of moonlight rather than patterns at the level of populations or individuals. More interesting, the importance of examining a system comprising two predators and their common prey lies in the possibility that multiple predators may have effects that cannot be predicted simply by summing up the effects of single predator types on the same prey (Sih et al. 1998). 
The study of moon-related patterns of activity may help to understand the coexistence of carnivores

Fedriani et al. (1999) suggested that one of the possible mechanisms explaining the coexistence of lynxes and red foxes in Doñana was that foxes reduced the risk of being killed by a lynx by their spatial behaviour, as has been recently observed in Doñana (Viota et al. 2012), where lynx and Egyptian mongoose coexist (Herpestes ichneumon). Specifically, Fedriani et al. (1999) proposed that foxes reduced using the richest rabbit habitat during the activity period (i.e. at night) to avoid encounters with lynxes, which mainly frequented this habitat.

However, they also hypothesized that some other temporal avoidance behaviours should act to facilitate the coexistence of these two sympatric carnivore species (Fedriani 1997). Information from our novel analyses on moon-mediated patterns of activity shed light onto the relationships between top and mesopredators. The coexistence of predators that overlap in foraging habitats certainly may be facilitated by the changing light of contrasting lunar phases. Different moonlight responses may be especially useful in giving an alternative explanation as to how carnivores may coexist when, as is the case in this study, overlapping food among predators challenges the view that food is the resource towards which spatial and behavioural means of distinguishing niches by predators are ultimately directed (e.g. Hespenheide 1975). The lunar effects documented in this study are indeed consistent with MacArthur and Pianka (1966) and MacArthur and Wilson (1967), who predicted that for coexisting predators it is easier to adjust behaviour to reduce competition, than to change food habits.

The temporal gap in the prey response

Interestingly, rabbits delayed their response to the full/new moon and/or to predator activity peaks that correspond to the full/new moon. A similar lack of synchrony might be a neglected feature of other predator-prey interactions if one species responds to the other species with a time lag. This delayed response of the rabbit to the lunar cycle might result more from being alert to increasing predation than directly from the effect of lunar brightness, i.e. the rabbits are not necessarily aware that they risk more during the brightest nights, as is generally believed (e.g. Clarke 1983; Kotler et al. 2010). If predation increases because the moonlight assists predators to find and pursue prey, the prey respond to this increased predation rate by reducing their activity. This reduction, however, can take several days, and this time delay could be the source of the temporal gap we observed in the moon's effect on rabbits.
This situation can also hold for sit-and-wait predators such as lynxes (López-Bao 2010) and eagle owls (Bubo bubo; Penteriani et al. 2008) because rabbits live in groups, and a predation event may be observed by the neighbouring conspecifics of the targeted individual. This delay in the rabbit response under predation agrees with the previously studied interactions between a diurnal avian predator (the Spanish imperial eagle Aquila adalberti) and rabbits (Penteriani et al. 2006); the primary factor influencing a predator's occupancy of a foraging patch being the time taken by the rabbits to change their activity timetable under predation pressure. Foraging predators can affect prey availability and, consequently, capture success (Neill and Cullen 1974; Parrish 1992; Loggerwell and Hargreaves 1996; Ainley et al. 2003). Thus, if the lowered availability of rabbits decreases predation, the rabbits resume their previous behaviour and consequently become available again to the predators. Clearly, all these cycles of availability show a temporal range of perception of predation risk and/or recovery from fear of predation. This predatorprey 'game' might be the source of the temporal gap between moon phases and rabbit behaviours. Relationships between predators (for better hunting) and prey (for better predator avoidance) are typical examples of coordinated behaviours (Rosenzweig et al. 1997; Bahr and Bekoff 1999; Brown et al. 2001). Thus, these results support previous evidence that predators may influence the activity and spatial patterns of prey (Lagos et al. 1995; Brown and Kotler 2004; Yunger 2004), and also highlight the importance of comparative studies of predators and prey. Thus, we revealed a functional response (i.e. the rabbits shift to a more concealed behaviour pattern if predation pressure increases) that is influenced in part by spontaneous patterns: the rabbits could not be aware of the pattern that they created (i.e. behavioural variations following lunar cycles).

\section{Other effects}

It is also interesting to underscore the important role evidently played by the diverse constraints resulting from the diverse tasks required by the reproductive period. The different periods of the year always played an important role in determining the behaviours of all three species. For example, both the predators and the prey restricted their activities to the core areas during reproduction. Note, in addition, that the contribution of the landscape structure in terms of ecotone density affected the behaviours of foxes and rabbits similarly, decreasing their nightly total distances travelled. Specifically, the edge density played a role in determining both total distance and speed: in the most heterogeneous landscapes (higher values of edge density), the rabbits moved shorter distances and at a slower speed. Previous radio-tracking studies showed the importance of 
cover for rabbits (Sacramento et al. 1996; Lombardi et al. 2007). These studies showed that vegetation patches providing refuges were used in higher proportions than their availability. Because rabbits are hunted by most Mediterranean mammals and avian predators (Fedriani et al. 1999; Forero et al. 2002), their habitat use and spatial activity appear to be substantially related to the availability of refuges and to predator avoidance (Lombardi et al. 2007). In conjunction with the previously unexplored effect of the moonlight, predation could have determined the differences formerly recorded in home range size and core areas, primarily as a function of the availability of shelter providing predator avoidance rather than because of pasture availability (Lombardi et al. 2007). Finally, in light of the results of this study, the previously unexplained long foraging excursions into the pasture areas and a greater use of space at night (Lombardi et al. 2007) may now be related to the darkest nights. During these nights, the rabbits increased their activity because obscurity offered the safest opportunities for movement even in open (risky) habitats.

The results of the current work present two non-mutually exclusive possibilities. First, prey appear to be adapted to reduce their activity near the full moon because of the high associated risk of predation. Consequently, they become less active and show a greater tendency to remain concealed (Clarke 1983). Second, though, the temporal gap shown by the rabbit response to moon phases under brighter moons must be considered. The predators initially take advantage of the easier visual location of prey to increase their (successful) predation rates. In response, the prey modify their behaviour and become increasingly wary. Thus, the potential for predators to visually detect prey increases with increasing light, but the probability of encountering active prey then decreases and the effort associated with such encounters increases (Lockard and Owings 1974; Clarke 1983; Sábato et al. 2006) because of the increasing fear shown by the prey in response to the increase in predation rates. On the other hand, foxes appeared to display a trade-off between the two needs to maximise and minimise encounters with their prey (rabbits) and top predators (lynx), respectively.

The results of this study suggest that predator-prey interactions still merit deeper investigation. As emphasised by Lima (2002), and recently shown by Berger-Tal et al. (2010), Kotler et al. (2010) and Cozzi et al. (2012), a more global approach to predator-prey interactions might change the way we think about such interactions and bring to light complex foraging games between multiple predators and their prey.

Acknowledgments We would like to thank E. Revilla and J. C. Rivilla, as well as numerous students, who collaborated with the carnivore field work. J. Sundell and two anonymous referees provided useful comments that improved the manuscript. This study was funded by six research projects of the Spanish Ministry of Science and Innovation (PB90-1018, PB94-0480, PB97-1163, CGL2004-02780/ BOS, CGL2004-00346/BOS and CGL2008-02871/BOS; with FEDER co-financing) and one of the Spanish Ministry of the Environment, National Parks Research Programme (project 17/2005), a grant of the Ministry of Education and Science-C.S.I.C. (Proyectos Intramurales Especiales, DG-2606-PC), and the Junta of Andalucía (Excellence Project, RNM-5090). V. P. was the recipient of a grant from the Spanish Secretaría General de Universidades, Ministry of Education (Salvador de Madariaga Program); A. K. received a postdoctoral grant (no. 132828) from the Academy of Finland. M. M. D. received a post-doctoral fellowship from the Spanish Ministry of Science and Innovation and a post-doctoral grant (no. 140367) from the Academy of Finland, and J. V. L. B. received a post-doctoral fellowship from the Spanish Ministry of Education. The Regional Government of Andalucía partly funded the supplementary feeding programme of lynx (LIFE-02NAT/8609). Land Rover España kindly lent two vehicles for the research on the lynx. Methods of capture and handling of lynx complied with the norms of the Spanish Animal Protection RD1201/2005 and were specifically approved by the competent administration (the Regional Government of Andalusia and the Doñana National Park) under permit no. RS-2093/04.

\section{References}

Abrams PA (2000) The evolution of predator-prey interactions: theory and evidence. Annu Rev Ecol Syst 31:79-105. doi: 10.1146/annurev.ecolsys.31.1.79

Ainley DG, Ford RG, Brown ED, Suryan RM, Irons DB (2003) Prey resources, competition, and geographic structure of kittiwake colonies in Prince William Sound. Ecology 84:709-723

Anderson DP, Forester JD, Turner MG, Frair JL, Merrill EH, Fortin D, Mao JS, Boyce MS (2005) Factors influencing female home range sizes in elk (Cervus elaphus) in North American landscapes. Landsc Ecol 20:257-271. doi:10.1007/s10980-005-0062-8

Bahr DB, Bekoff M (1999) Predicting flock vigilance from simple passerine interactions: modelling with cellular automata. Anim Behav 58:831-839. doi:10.1006/anbe.1999.1227

Bates DM, Sarkar D (2007) lme4: linear mixed-effects models using S4 classes, $\mathrm{R}$ package version 0.99875-6. http://lme4.rforge.r-project.org/

Beltran JF, Delibes M (1994) Environmental determinants of circadian activity of free-ranging Iberian lynxes. J Mammal 75:382-393

Berger-Tal O, Mukherjee S, Kotler BP, Brown JS (2010) Complex state-dependent games between owls and gerbils. Ecol Lett 13:302-310. doi:10.1111/j.1461-0248.2010.01447.x

Bos DG, Carthew SM (2003) The influence of behaviour and season on habitat selection by a small mammal. Ecography 26:810-820. doi:10.1111/j.0906-7590.2003.03584.x

Bouskila A (2001) A habitat selection game of interactions between rodents and their predators. Ann Zool Fenn 38:55-70

Brown JS, Kotler BP (2004) Hazardous duty pay and the foraging cost of predation. Ecol Lett 7:999-1014. doi:10.1111/j.14610248.2004.00661.x

Brown JS, Kotler BP, Bouskila A (2001) Ecology of fear: foraging games between predators and prey with pulsed resources. Ann Zool Fenn 38:71-87

Caro T (2005) Antipredator defences in birds and mammals. University of Chicago Press, Chicago

Clarke JA (1983) Moonlight's influence on predator/prey interaction between short-eared owls (Asio flammeus) and deermice (Peromyscus maniculatus). Behav Ecol Sociobiol 13:205-209 
Cozzi G, Broekhuis F, McNutt JW, Turnbull LA, MacDonald DW, Schmid B (2012) Fear of the dark or dinner by moonlight? Reduced temporal partitioning among Africa's large carnivores. Ecology 93:2590-2599

Crawley MJ (2007) The R book. Wiley, London

Crooks KC, Soulé ME (1999) Mesopredator release and avifaunal extinctions in a fragmented system. Nature 400:563-566. doi: $10.1038 / 23028$

Crowl TA, Covich AP (1994) Response of a freshwater shrimp to chemical and tactile stimuli from a large decapod predator. J North Am Benthnol Soc 13:291-298

deBruyn AMH, Meeuwig JJ (2001) Detecting lunar cycles in marine ecology: periodic regression versus categorical ANOVA. Mar Ecol Prog Ser 214:307-310

Delgado MM, Penteriani V, Nams VO, Campioni L (2010a) Changes of movement patterns from early dispersal to settlement. Behav Ecol Sociobiol 64:35-43. doi:10.1007/s00265-009-0815-5

Delgado MM, Penteriani V, Revilla E, Nams VO (2010b) The effect of phenotypic traits and external cues on natal dispersal movements. J Anim Ecol 79:620-632. doi:10.1111/j.1365-2656. 2009.01655.x

Delibes M (1980) Feeding ecology of the Spanish lynx in the Coto Doñana. Acta Theriol 25:309-324

Di Bitetti MS, Paviolo A, De Angelo C (2006) Density, habitat use and activity patterns of ocelots (Leopardus pardalis) in the Atlantic Forest of Misiones, Argentina. J Zool 270:153-163. doi: 10.1111/j.1469-7998.2006.00102.x

Doncaster CP (1994) Factors regulating local variations in abundance: field tests on hedgehogs Erinaceus europaeus. Oikos 69: 182-192

Donovan TM, Thompson FR, Faaborg J, Probst JR (1995) Reproductive success of migratory birds in habitat sources and sinks. Conserv Biol 9:1380-1395

Elkie P, Rempel R, Carr A (1999) Patch analyst user's manual: a tool for quantifying landscape structure. Ontario Ministry of Natural Resources Northwest Science and Technology, Thunder Bay, Ontario

Fedriani JM (1997) Relaciones interespecíficas entre el lince Ibérico, Lynx pardina, el zorro, Vulpes vulpes, y el tejón, Meles meles, en el Parque Nacional de Doñana. PhD thesis, University of Seville, Seville

Fedriani JM, Palomares F, Delibes M (1999) Niche relations among three sympatric Mediterranean carnivores. Oecologia 121:138-148. doi:10.1007/s004420050915

Fedriani JM, Fuller TK, Sauvajot RM, York EC (2000) Competition and intraguild predation among three sympatric carnivores. Oecologia 125:258-270. doi:10.1007/s004420000448

Ferreras P, Beltrán JF, Aldama JJ, Delibes M (1997) Spatial organization and land tenure system of the endangered Iberian lynx (Lynx pardinus, Temminck, 1824). J Zool 243:163-189. doi:10.1111/j.1469-7998.1997.tb05762.x

Ferreras P, Delibes M, Palomares F, Fedriani JM, Calzada J, Revilla E (2004) Proximate and ultimate causes of dispersal in the Iberian lynx (Lynx pardinus). Behav Ecol 15:31-40

Forero MG, Donázar JA, Hiraldo F (2002) Causes and fitness consequences of natal dispersal in a population of black kites. Ecology 83:858-872

Fretwell SD (1987) Food-chain dynamics: the central theory of ecology. Oikos 50:291-301

Ginsberg JR, Macdonald D (1991) Foxes, wolves, jackals and dogs. IUCN, Gland

Grassman LI, Tewes ME, Silvy NJ (2005) Ranging, habitat use and activity patterns of binturong and yellow-throated marten in north-central Thailand. Wildl Biol 11:49-57
Griffin PC, Griffin SC, Waroquiers C, Mills LS (2005) Mortality by moonlight: predation risk and the snowshoe hare. Behav Ecol 16:938-944

Hespenheide HA (1975) Prey characteristics and predator niche width. In: Cody ML, Diamond JM (eds) Ecology and evolution of communities. Harvard University Press, Cambridge, pp 158-180

Hugie DM, Dill LM (1994) Fish and game: a game theoretic approach to habitat selection by predators and prey. J Fish Biol 45:151-169

Kenward RE (2001) A manual of wildlife radio-tagging. Academic Press, London

Kie JG, Bowyer RT, Nicholson MC, Boroski BB, Loft ER (2002) Landscape heterogeneity at differing scales: effects on spatial distribution of mule deer. Ecology 83:530-544

Kleiman DG, Eisenberg JF (1973) Comparison of canid and felid social system from an evolutionary perspective. Anim Behav 21:637-659

Kohler SL, McPeek MA (1989) Predation risk and the foraging behaviour of competing stream insects. Ecology 70:1811-1825

Kolb HH (1992) The effect of moonlight on activity in the wild rabbit (Oryctolagus cuniculus). J Zool 228:661-665

Kotler BP (1997) Patch use by gerbils in a risky environment: manipulating food and safety to test four models. Oikos 78:274-282

Kotler BP, Brown JS, Smith RJ, Wirtz WO (1988) The effects of morphology and body size on rates of owl predation on desert rodents. Oikos 53:145-152

Kotler BP, Brown JS, Hosson O (1991) Factors affecting gerbil foraging behaviour and rates of owl predation. Ecology 72:2249-2260

Kotler BP, Brown JS, Dall SRX, Gresser S, Ganey D, Bouskila A (2002) Foraging games between gerbils and their predators: temporal dynamics of resource depletion and apprehension in gerbils. Evol Ecol Res 4:495-518

Kotler BP, Brown J, Mukherjee S, Berger-Tal O, Bouskila A (2010) Moonlight avoidance in gerbils reveals a sophisticated interplay among time allocation, vigilance and state-dependent foraging. Proc R Soc B 277:1469-1474. doi:10.1098/rspb.2009.2036

Krebs CJ, Boutin S, Boonstra R, Sinclair ARE, Smith JNM, Dale MRT, Martin K, Turkington R (1995) Impact of food and predation on the snowshoe hare cycle. Science 269:1112-1115

Kuparinen A, Klefoth T, Arlinghaus R (2010) Abiotic and fishingrelated correlates of angling catch rates in pike (Esox lucius). Fish Res 105:111-117

Lagos VO, Contreras LC, Meserve PL, Gutiérrez JR, Jaksic FM (1995) Predation effects on space use by small mammals: a field experiment with a Neotropical rodent, Octodon degus. Oikos 74:259-264

Lima SL (1998) Nonlethal effects in the ecology of predator-prey interactions. Bioscience 48:25-34

Lima SL (2002) Putting predators back into behavioural predator-prey interactions. Trends Ecol Evol 17:70-75

Lima SL (2009) Predators and the breeding bird: behavioural and reproductive flexibility under the risk of predation. Biol Rev 84:485-513

Lima SL, Dill LM (1990) Behavioural decisions made under the risk of predation: a review and prospectus. Can J Zool 68:619-640

Lockard RB, Owings DH (1974) Moon-related surface activity of bannertail (Dipodomys spectabilis) and Fresno (D. nitratoides) kangaroo rats. Anim Behav 22:26-273

Loggerwell EA, Hargreaves NB (1996) The distribution of seabirds relative to their fish prey off Vancouver Island: opposing results at large and small spatial scales. Fish Oceanogr 5:163-175 
Lombardi L, Fernández N, Moreno S, Villafuerte R (2003) Habitatrelated differences in rabbit (Oryctolagus cuniculus) abundance, distribution, and activity. J Mammal 84:26-36

Lombardi L, Fernández N, Moreno S (2007) Habitat use and spatial behaviour in the European rabbit in three Mediterranean environments. Basic Appl Ecol 8:453-463

López-Bao JV (2010) Food supplementation in the Iberian lynx (Lynx pardinus): design, side effects and effectiveness. PhD thesis, University of Seville, Seville

López-Bao JV, Rodríguez A, Palomares F (2008) Behavioural response of a trophic specialist, the Iberian lynx, to supplementary food: patterns of food use and implications for conservation. Biol Conserv 141:1857-1867

López-Bao JV, Rodríguez A, Palomares F (2009) Competitive asymmetries in the use of supplementary food by the endangered Iberian lynx (Lynx pardinus). PLoS ONE 4:e7610

López-Bao JV, Palomares F, Rodríguez A, Delibes M (2010) Effects of food supplementation on home range size, productivity and recruitment in a small population of Iberian lynx. Anim Conserv 13:35-42

López-Bao JV, Palomares F, Rodríguez A, Ferreras P (2011) Intraspecific interference influences the use of prey hotspots. Oikos 120:489-1496

MacArthur RH, Pianka ER (1966) On optimal use of a patchy environment. Am Nat 100:603-609

MacArthur RH, Wilson EO (1967) The theory of island biogegraphy. Princeton University Press, Princeton

Molsher RL, Gifford EJ, McIlroy JC (2000) Temporal, spatial and individual variation in the diet of red foxes (Vulpes vulpes) in central New South Wales. Wildl Res 27:593-601

Monclús R, Palomares F, Tablado Z, Martínez-Fontúrbel A, Palme R (2009) Testing the threat-sensitive predator avoidance hypothesis: physiological responses and predator pressure in wild rabbits. Oecologia 158:615-623

Morosinotto C, Thomson RL, Korpimäki E (2010) Habitat selection as an antipredator behaviour in a multi-predator landscape: all enemies are not equal. J Anim Ecol 79:327-333

Mukherjee S, Zelcer M, Kotler BP (2009) Patch use in time and space for a meso-predator in a risky world. Oecologia 159:661-668

Murray DL, Boutin S, O’Donoghue M, Nams VO (1995) Hunting behaviour of a sympatric felid and canid in relation to vegetation cover. Anim Behav 50:1203-1210

Neill SRStJ, Cullen JM (1974) Experiments on whether schooling by their prey affects hunting behaviour of cephalopod and fish predators. J Zool 172:549-569

Paine RT (1966) Food web complexity and species diversity. Am Nat 100:65-75

Palomares F, Caro T (1999) Interspecific killing among mammalian carnivores. Am Nat 153:492-508

Palomares F, Gaona P, Ferreras P, Delibes M (1995) Positive effects on game species of top predators by controlling smaller predator populations: an example with lynx, mongooses, and rabbits. Conserv Biol 9:295-305. doi:10.1046/j.1523-1739.1995.9020295.x

Palomares F, Ferreras P, Fedriani JM, Delibes M (1996) Spatial relationships between Iberian lynx and other carnivores in an area of south-western Spain. J Appl Ecol 33:5-13

Palomares F, Delibes M, Ferreras P, Fedriani JM, Calzada J, Revilla E (2000) Iberian lynx in a fragmented landscape: predispersal, dispersal, and postdispersal habitats. Conserv Biol 14:809-818

Palomares F, Delibes M, Ferreras P, Fedriani JM, Calzada J, Revilla E (2001) Spatial ecology of Iberian lynx and abundance of European rabbits in south western Spain. Wildl Monogr 148:1-36

Pangle KL, Peacor SD, Johannsson OE (2007) Large nonlethal effects of an invasive invertebrate predator on zooplankton population growth rate. Ecology 88:402-412
Parrish JK (1992) Do predators 'shape' fish schools: interactions between predators and their schooling prey. Neth J Zool 42:358-370

Peacor SD, Werner EE (2004) Context dependence of nonlethal effects of a predator on prey growth. Isr J Zool 50:139-167

Peckarsky BL, Abrams PA, Bolnick DI, Dill LM, Grabowski JH, Luttbeg B, Orrock JL, Peacor SD, Preisser EL, Schmitz OJ, Trussell GC (2008) Revisiting the classics: considering nonconsumptive effects in textbook examples of predator-prey interactions. Ecology 89:2416-2425

Pedersen ÅØ, Ims RA, Yoccoz NG, Hausner VH, Juell KH (2010) Scale-dependent responses of predators and their prey to spruce plantations in subarctic birch forests in winter. Ecoscience $17: 123-136$

Penteriani V, Fortuna MA, Melián CJ, Otalora F, Ferrer M (2006) Can prey behaviour induce spatially synchronic aggregation of solitary predators? Oikos 113:497-505

Penteriani V, Delgado MM, Bartolommei P, Maggio C, AlonsoAlvarez C, Holloway GJ (2008) Owls and rabbits: predation against substandard individuals of an easy prey. J Avian Biol 39:215-221. doi:10.1111/j.0908-8857.2008.04280.x

Penteriani V, Kuparinen A, Delgado MM, Lourenço R, Campioni L (2011) Individual status, foraging effort and need for conspicuousness shape behavioural responses of a predator to moon phases. Anim Behav 82:413-420

Pettersson LB, Nilsson PA, Briinmark C (2000) Predator recognition and defence strategies in crucian carp, Carassius carassius. Oikos 88:200-212

Pinheiro JC, Bates DM (2004) Mixed-effects models in S and S-PLUS. Springer, New York

Pinheiro J, Bates D, DebRoy S, Sarkar D, the R Core team (2009) nlme: linear and nonlinear mixed effects models. $\mathrm{R}$ package version 3.1-96

Polis GA, Holt RD (1992) Intraguild predation: the dynamics of complex trophic interactions. Trends Ecol Evol 7:151-154

Polis GA, Myers CA, Holt RD (1989) The ecology and evolution of intraguild predation: potential competitors that eat each other. Annu Rev Ecol Syst 20:297-330. doi:10.1146/annurev.es.20. 110189.001501

R Development Core Team (2009) R: a language and environment for statistical computing. R Foundation for Statistical Computing, Vienna. http://www.R-project.org

Rau JR, Beltran JF, Delibes M (1985) Can the increase of fox density explain the decrease in lynx numbers at Doñana? Rev Ecol Terre Vie 40:145-150

Relyea RA (2001) Morphological and behavioral plasticity of larval anurans in response to different predators. Ecology 82:523-540

Relyea RA (2003a) Predators come and predators go: the reversibility of predator-induced traits. Ecology 84:1840-1848

Relyea RA (2003b) How prey respond to combined predators: a review and an empirical test. Ecology 84:1827-1839

Rodríguez A, Delibes M (2002) Internal structure and patterns of contraction in the geographic range of the Iberian lynx. Ecography 25:314-328

Rosenzweig ML, Abramsky Z, Subach A (1997) Safety in numbers: sophisticated vigilance by Allenby's gerbil. Proc Natl Acad Sci USA 94:5713-5715

Russell JC, Lecomte V, Dumont Y, Le Corre M (2009) Intraguild predation and mesopredator release effect on long-lived prey. Ecol Model 220:1098-1104

Sábato MAL, de Melo LFB, Magni EMV, Young RJ, Coelho CM (2006) A note on the effect of the full moon on the activity of wild maned wolves, Chrysocyon brachyurus. Behav Proc 73:228-230

Sacramento M, Villafuerte R, Delibes M (1996) Cover is safe during the day but dangerous at night: the use of vegetation by European wild rabbits. Can J Zool 74:1656-1660 
Schmitz OJ, Beckerman AP, O’Brien KM (1997) Behaviorally mediated trophic cascades: effects of predation risk on food web interactions. Ecology 78:1388-1399

Seaman DE, Powell RA (1996) An evaluation of the accuracy of Kernel density estimators for home range analysis. Ecology 77:2075-2085

Sergio F, Marchesi L, Pedrini P (2003) Spatial refugia and the coexistence of a diurnal raptor with its intraguild owl predator. J Anim Ecol 72:232-245. doi:10.1046/j.1365-2656.2003.00693.x

Sergio F, Marchesi L, Pedrini P, Penteriani V (2007) Coexistence of a generalist owl with its intraguild predator: distance-sensitive or habitat-mediated avoidance? Anim Behav 74:1607-1616

Sih A (1987) Predators and prey lifestyles: an evolutionary and ecological overview. In: Kerfoot WC, Sih A (eds) Predation: direct and indirect impacts on aquatic communities. University Press of New England, Lebanon, pp 203-224

Sih A, Englund G, Wooster D (1998) Emergent impacts of multiple predators on prey. Trends Ecol Evol 13:350-355

Skelly DK, Werner EE (1990) Behavioral and life-historical responses of larval American toads to an odonate predator. Ecology 71:2313-2322

Smee D (2012) Environmental context influences the outcomes of predator-prey interactions and degree of top-down control. Natl Educ Knowl 3:58

Soriguer RC (1981) Estructuras de sexos y edades en una población de conejos (Oryctolagus cuniculus L.) de Andalucía Occidental. Doñana Acta Vert 8:225-236

Taylor RJ (1984) Predation. Chapman \& Hall, London
Turner AM, Fetterolf SA, Bernot RJ (1999) Predator identity and consumer behavior: differential effects of fish and crayfish on habitat use of a freshwater snail. Oecologia 118:242-247

Twigg LE, Lowe TJ, Gray GS, Martin GR, Wheeler AG, Barker W (1998) Spotlight counts, site fidelity and migration of European rabbits (Oryctolagus cuniculus). Wildl Res 25:113-122

van Baalen M, Sabelis MW (1999) Nonequilibrium population dynamics of 'ideal and free' prey and predators. Am Nat 154: 69-88

Vasquez RA (1994) Assessment of predation risk via illumination level-facultative central place foraging in the cricetid rodent Phyllotis darwini. Behav Ecol Sociobiol 34:375-381

Vermeij GJ (1987) Evolution and escalation. Princeton University Press, Princeton

Villafuerte R (1994) Riesgo de predación y estrategias defensivas del conejo (Oryctolagus cuniculus) en el Parque Nacional de Doñana. PhD thesis, University of Córdoba, Córdoba

Viota M, Rodríguez A, López-Bao JV, Palomares F (2012) Shift in microhabitat use as a mechanism allowing the coexistence of victim and killer carnivore predators. Open J Ecol 2:115-120

Worton BJ (1989) Kernel methods for estimating the utilization distribution in home-range studies. Ecology 70:174-168

Yunger JA (2004) Movement and spatial organization of small mammals following vertebrate predator exclusion. Oecologia 139:647-654

Zuur AF, Ieno EN, Walker NJ, Saveliev AA, Smith GM (2009) Mixed effects models and extensions in ecology with $\mathrm{R}$. Springer, New York 